\title{
Differentiated sources of funding road infrastructure
}

\author{
Marina Shibaeva ${ }^{1, *}$, Ella Okolelova $^{1}$ and Oleg Shalnev ${ }^{1}$ \\ ${ }^{1}$ Voronezh State Technical University, Moscow Avenue, 14, Voronezh, 394026, Russia
}

\begin{abstract}
Article reveals the growing need for increased investment in projects for the modernization and development of the motor road network and identifies the problem of high capital intensity of road construction facilities and the duration of the investment payback period that hinder the inflow of private investments. By analyzing the economic aspects of road infrastructure, the authors have developed the economic and mathematical model for optimizing the placement of asphalt-concrete plants and the cost of producing the asphalt mix, the algorithm for optimizing the cost of road facility construction, the algorithm for selecting effective investment options for commercial roadside projects.
\end{abstract}

\section{Introduction}

The development of infrastructure, an important component of which is the transport infrastructure, ensures the economic growth, improves the investment attractiveness and competitiveness of the economy, creates conditions for the transition to an innovative development path, ensures the successful integration of Russia into the world economy, and smoothens the differentiation of the development of the country's regions [1,2].

An analysis of the experience of foreign countries showed that there is a directly proportional dependence of the country's socioeconomic development on the development of its road infrastructure, through which a new space is created to implement the opportunities for the development of various sectors of the economy, thereby increasing mobility and business and social activity in the society [3].

Currently, Russia is experiencing a backlog in the development of the road network, a decrease in its transport and operational characteristics, an increase in the accident rate due to inadequate financing of the road sector compared to the increase in motor transport number. The existing trends have resulted in the non-conformance of the country's road network with the needs of the development of the Russian economy [3].

In foreign countries, the development of a road network that meets the needs of the economy and the population is one of the priority tasks of the economic policy. The implementation of programs to increase the length and improve the quality of the road network has made it possible to achieve significant results, both in the economy and in the social sphere (The program of activity of the State Company Russian Highways for the longterm period (2010-2020), 2009).

\footnotetext{
* Corresponding author: uvarova_s.s@mail.ru
} 


\section{Materials and methods}

The annual losses of Russia due to the insufficient development of the road network are estimated at 450-500 billion rubles (Road infrastructure of Russia, 2016).

According to the Russian Association of Contracting Organizations in the Road Sector, the losses due to the unsatisfactory condition of the road network reach 120 billion rubles a year (Federal Road Agency of the Ministry of Transport of the Russian Federation, 2017). There is a need for a significant investment in the modernization and development of the road network. Taking into account the scale of the problems to solve and the world experience, there it has become necessary to attract extrabudgetary sources of the road infrastructure financing. Creating toll road facilities could be one solution, which users, as well as regional representative and executive authorities, find acceptable (The concept of the road building reform, 2005).

At present, the implementation of socially significant infrastructure projects based on the principles of public and private partnership (PPP) is one of the most important strategic priorities of the Ministry of Transport of the Russian Federation The road sector is a priority area of the PPP development in the transport sector. However, the low investment prospects of the road sector, due to the high capital intensity of road facilities and the long payback period, hinders the inflow of private investments. Therefore, there is a need to find ways to improve the efficiency of investments in the construction of road facilities and, as a consequence, shorten their payback periods (On the Approval of the Transport Strategy of the Russian Federation for the Period until 2030, 2008).

One of the ways to improve the efficiency of investments in the construction of road facilities is the implementation of high-yield satellite projects in the roadside, such as hotel facilities, shopping malls, recreation and entertainment parks, filling stations, etc. Road service is an activity related to meeting the needs of road users transport. Currently, only the increase in the number of filling stations corresponds to such an intensive increase in the fleet of cars [4].

Consider an algorithm for increasing the income from investments in the commercial use of the roadside road service facilities (see Figure 1).

Where $N^{p}{ }_{k}$ is the estimated number of road service objects of the $k t h$ type, pcs., $N^{p}{ }_{k}=\mathrm{i}$; $\mathrm{N}$ is the section length, $\mathrm{km}$;

$\lambda(\mathrm{t})$ is the harmonic equation of the functional dependence of the average daily traffic intensity on time (day of the year), cars/day;

$t$ is the time, in days $(\mathrm{t} \in[1, \mathrm{~T}]) ; T$ is the calculation horizon, in days $(\mathrm{T}=\mathrm{Y} * 365)$;

$Y$ is the number of years of the project implementation, $y$ is the estimated year of the project implementation, in years;

$V_{b}$, is the average (weighted average by the share of cars of the corresponding category) value of a fuel tank volume, in liters;

$\kappa_{b}$ is the average coefficient of the fuel tank usage;

$\kappa_{n a}$ is the coefficient showing the average number of cars out of order in the flow per day;

1.5 is the coefficient that takes into account the number of people in a car;

$\kappa_{n c}$ is the coefficient showing the average number of food spot visitors per day;

$M_{a}$ is the capacity of a single filling station, in liters/day;

$M_{t}$ is the capacity of one service station, in cars/day;

$M_{k}$ is the capacity of one food spot, in people/day;

$K B_{k \mathrm{i}}$ is the average estimated capital investments for the construction of the ith object of the $k$ th type ( $\mathrm{k} \in[1,3], 1$ - filling stations, 2 - service stations, 3 - food spots), in thousand rubles; 
$K B_{\mathrm{k}}$ is the estimated capital investments for the construction of $i$ objects of the $k t h$ type, in thousand rubles;

$Z^{p r_{k} i}$ is the resulted annual total expenses on $i$ objects of the $k t h$ type, in thousand rubles;

$Z^{\mathrm{te}}{ }_{\mathrm{kiy}}$ is the total costs for $i$ objects of the $k t h$ type in the $y$ th year of the investment project, in thousand rubles;

$D_{k i}$ is the calculated value of the annual total income for $i$ objects of the $k t h$ type, in thousand rubles;

$K_{a}$ is the total number of filling stations, in pieces;

$K_{s n a}$ is the weighted average number of defective vehicles per day, in cars/day;

$K_{s n k}$ is the average number of food spot visitors per day, in people/day;

$H_{p}$ is the fuel allowance (weighted by the share of vehicles of the corresponding category), the value of the fuel tank volume, in liters $/ \mathrm{km}$;

$C_{t o}$ is the weighted average cost of one liter of fuel, in thousand rubles;

$C_{r a}$ is the weighted average cost of vehicle repair, in thousand rubles;

$C_{d}$ is the average lunch cost, in thousand rubles;

$r_{\mathrm{y}}$ is the discount factor for the $y$ th year.

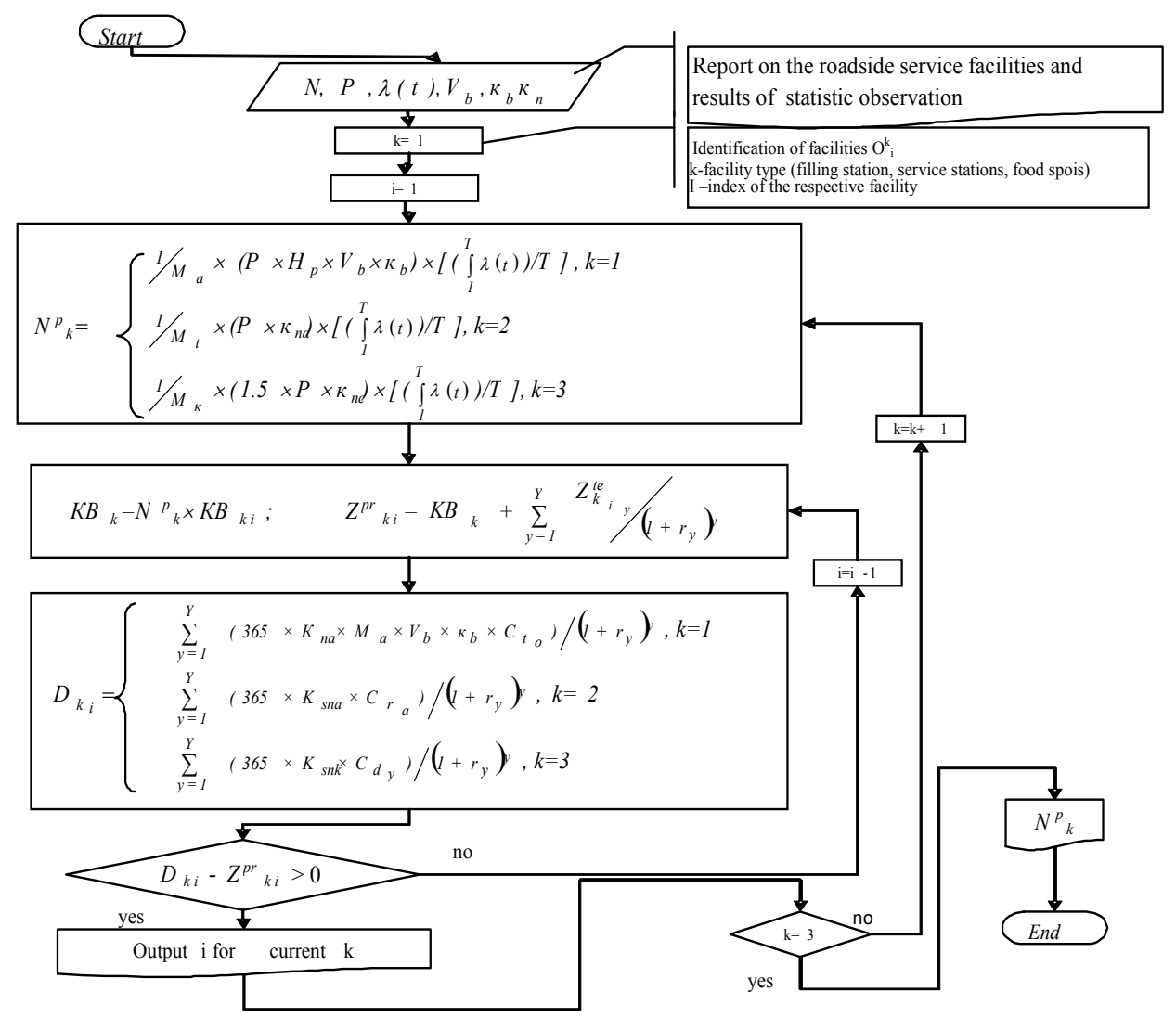

Fig. 1. Flowchart of the algorithm for increasing the income on investments at the commercial use of the roadside. 
Another direction to improve the efficiency of investments in the construction of road facilities is the optimization of their cost. A significant proportion of total PPP investments in road construction is the cost of bitumen and crushed stone, used both in pure form and for the asphalt mix production. Consequently, they largely determine the cost of road construction, and optimizing their cost would also optimize the cost of road works, and, consequently, the amount of investments [6].

The economic and mathematical model for optimizing the location and product output of the asphalt-concrete plants includes all critical elements: the cost of crushed stone and bitumen supplied to the asphalt-concrete plants; the maximum capacity of asphalt-concrete plants, the cost of asphalt mix supplied to the construction site (Korotkij, 2007).

The objective function of the task is to minimize total costs:

$$
F=\sum_{j=1}^{n}\left[\left(t_{\mathrm{ij}}^{z} \times d^{z}\right) \sum_{i=1}^{m} x_{j i}\right]+\sum_{j=1}^{n}\left[\left(t_{\mathrm{ij}}^{b} \times d^{b}\right) \sum_{i=1}^{m} x_{j i}\right]+\sum_{i=1}^{m} \sum_{l=1}^{k} x_{i l} p_{i}+\sum_{i=1}^{m} \sum_{l=1}^{k} x_{i l} r_{i l} \rightarrow \min
$$

where $t_{j i}^{z}$ is the specific costs for transportation of crushed stone from the $j t h$ supplier to the ith asphalt-concrete plant, in rubles/ton;

$t^{b}{ }_{j i}$ is the unit costs for bitumen transportation from the $j t h$ supplier to the ith asphaltconcrete plant, in rubles/ton;

$d^{z}$ is the mass fraction of crushed stone in asphalt mix, in unit fractions;

$d^{b}$ is the mass fraction of bitumen in asphalt mix, in unit fractions;

$p_{i}$ is the unit costs for the production of asphalt mix at ith asphalt-concrete plant, in rubles/ton;

$r_{i l}$ is the specific costs for the delivery of asphalt mix produced at the $i t h$ asphalt-concrete plant to the lth facility, in rubles/ton;

$x_{j i}$ is the mass of asphalt mix transported from the $j$ th supplier to the ith asphalt-concrete plant, in tons;

$c_{i l}$ is the unit costs for the transportation of asphalt mix from ith asphalt-concrete plant to lth facility, in rubles/ton;

$x_{i l}$ is the amount of asphalt mix transported from the $i t h$ asphalt-concrete plant to the lth facility, in tons.

Limitations:

1. All asphalt-concrete plants are fully provided with crushed stone and bitumen:

$$
\sum_{j=1}^{n} \sum_{i=1}^{m} x_{j i}-(0.44+0.073) \sum_{i=1}^{m} \sum_{l=1}^{k} x_{i l}=0,
$$

2. All facilities are provided with asphalt mix:

$$
\sum_{i=1}^{m} x_{i l}=A_{l}, l=\overline{1, k}
$$

where: $A_{l}$ is the need for asphalt mix of the lth section of the motor road.

\section{Results and discussion}

It is proposed to find the extremum of function (1) by means of simulation modeling, according to the algorithm presented in Figure 2.

The construction of road infrastructure facilities is characterized by a long work cycle. Therefore, before the beginning of road construction work, it is necessary to analyze the price trends for basic materials and estimate their further change [7]. 
At present, approximating functions, which should well interpolate and extrapolate many classes of economic processes, become particularly relevant in modeling, analysis, and forecasting. With the new approach, it is proposed to use a universal piecewise-polynomial system of modeling, analyzing, visualizing, and predicting continuous spline functions.

The first step is to select the order of the spline base in order to achieve the desired smoothness and maintain normal computational efficiency. Cubic splines were chosen, since the lower-degree polynomials give too little flexibility in controlling the shape of the curve. $\mathrm{B}$-spline interpolation is a more complex type of interpolation, the difference of which is the connection of elementary B-splines not at points xi, but at other points ui, whose coordinates are entered by the user. Interp $(\mathrm{s}, \mathrm{x}, \mathrm{y}, \mathrm{t})$ is a function that approximates the data of vectors $\mathrm{x}$ and $\mathrm{y}$ using $\mathrm{B}$-splines. bspline $(\mathrm{x}, \mathrm{y}, \mathrm{u}, \mathrm{n})$ is the vector of $\mathrm{B}$-spline coefficients: $\mathrm{s}$ is the second derivative vector created by the bspline function; $x$ is the vector of real data of the argument whose elements are arranged in ascending order; $y$ is the vector of valid data values of the same size; $t$ is the value of the argument, at which the interpolating function is calculated; $u$ is the vector of the argument values, in which B-splines are spliced; $n$ is the order of interpolation and extrapolation polynomials $(1,2$, or 3$)$.

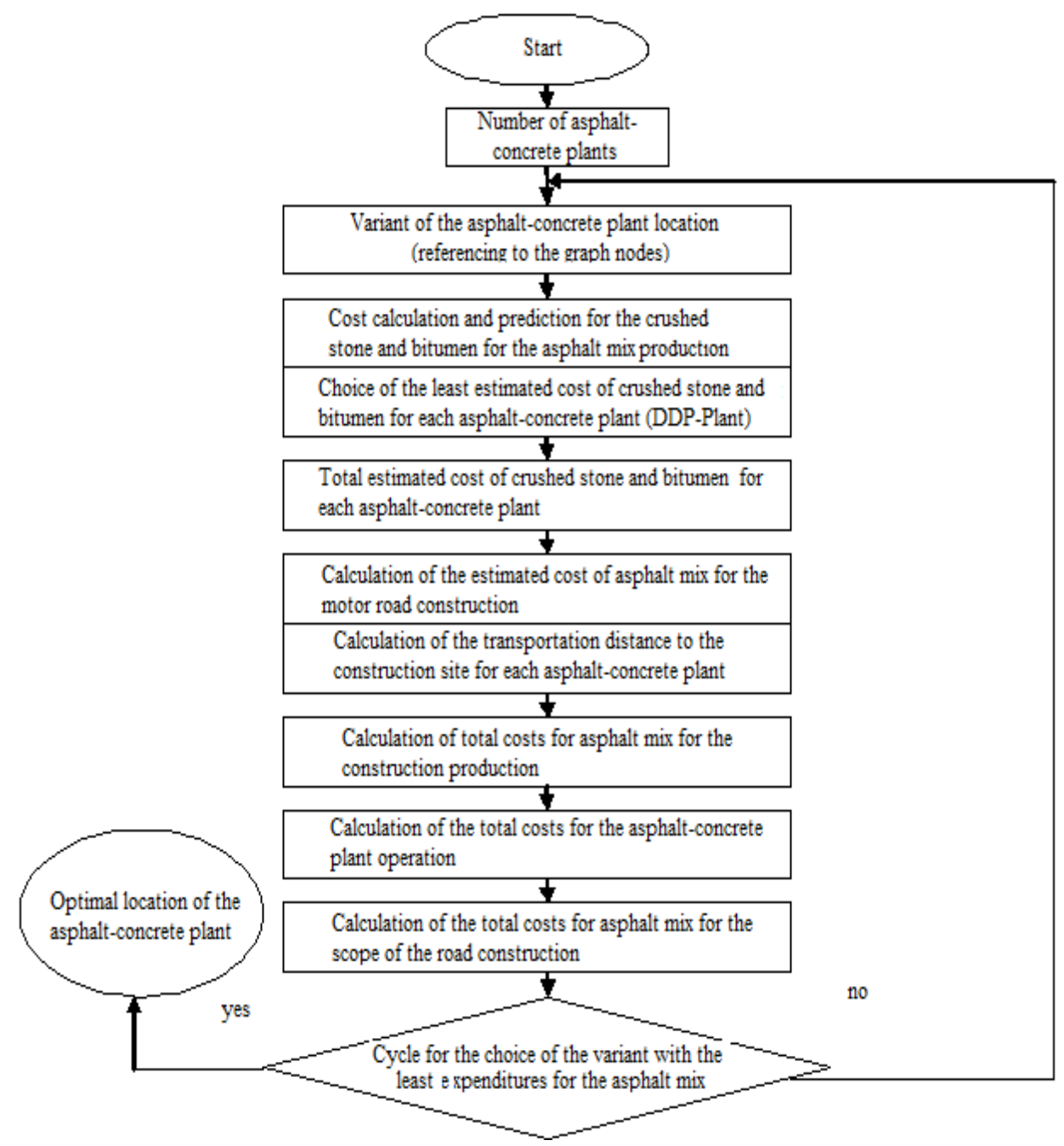

Fig. 2. Algorithm for optimizing the cost of the road infrastructure facility construction. 
Using the initial data presented in Figure 3, we estimate the cost of crushed stone and bitumen using the B-spline-extrapolation function in the MathCad program.

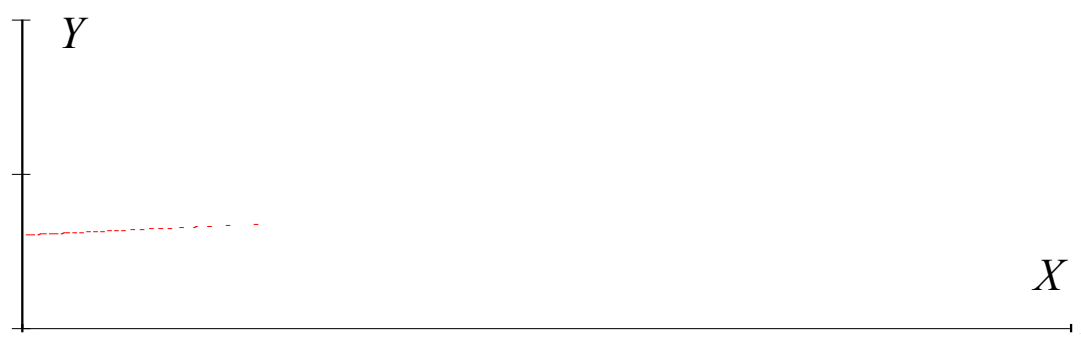

Fig. 3. B-spline-extrapolation of the total cost of crushed stone and bitumen, in rubles.

$\mathrm{X}$ is the time period vector.

$\mathrm{Y}$ is the vector of the total value of crushed stone and bitumen for the period under consideration.

$\mathrm{n}$ is the order of the extrapolation polynomials -3 .

Having estimated the change in the cost of construction materials that occupy the largest relative share in the cost of the road facility construction, it is possible to determine the estimated value of these facilities with high accuracy (Provotorov, 2010).

The practical implementation of the proposed model is carried out on the example of a fragment of the investment project for the construction of toll sections of the M-4 Don Highway based on PPPs, presented in Table 1. The toll section No. 1 is considered.

Table 1. The toll sections of the construction facility, the M-4 Don Highway.

\begin{tabular}{|c|c|c|}
\hline Nos. & Section length & Region \\
\hline Toll section No. 1 & $\mathrm{~km} 117+000-225+600$ & Tula Oblast \\
\hline Toll section No. 2 & $\mathrm{~km} 225+000-\mathrm{km} 322+600$ & Tula Oblast \\
\hline Toll section No. 3 & $\mathrm{~km} 545+200-\mathrm{km} 632+600$ & Voronezh Oblast \\
\hline Toll section No. 4 & $\mathrm{~km} 633+000-\mathrm{km} 658+000$ & Voronezh Oblast \\
\hline Toll section No. 5 & $\mathrm{~km} 658+000-\mathrm{km} 700+000$ & Voronezh Oblast \\
\hline Toll section No. 6 & $\mathrm{~km} 948+200-\mathrm{km} 1051+500$ & Rostov Oblast \\
\hline Toll section No. 7 & $\mathrm{~km} 1091+800-\mathrm{km} 1195$ & Krasnodar Krai \\
\hline
\end{tabular}

Currently, six asphalt-concrete plants are located within the radius of $50 \mathrm{~km}$ from the site. The projected volume of investments with such an arrangement of asphalt-concrete plants is approximately 3,171,000 rubles. Two crushed stone suppliers were considered: 1 - Pavlovsky Quarry, 2- Rostov Quarry; and two bitumen suppliers: 1 - the Town of Lobnya, 2 - the City of Ryazan. When the extremum of function (1) was found, according to calculations by the algorithm (Figure 2), the following optimal variant was obtained: 1 asphalt-concrete plant in Moscow Oblast and 3 asphalt-concrete plants in Tula Oblast, with a capacity of 320 tons/hour each. With such an arrangement, the investment portfolio will amount to 3,133,000 rubles; that is, it has decreased by $1.2 \%$.

\section{Conclusion}

The algorithm allows determining the income from the commercial use of the roadside based on the average daily intensity of the road section, on which the road service facilities will generate additional revenue. Also, the algorithm can be used to estimate an increase in the profitability of investments in road facilities from the commercial use of the roadside, optimizing their number. The application of the algorithm in the implementation of the 
investment project for the construction of the M-4 Don Highway allowed to increase the income from roadside facilities by $8.2 \%$ [8. 9]

Thus, the use of the proposed approaches makes it possible to increase the efficiency of investments in the construction of road facilities, shorten their payback periods, and, therefore, the industry will become more attractive to private investors.

\section{References}

1. V.V. Gasilov, M.A. Shibaeva, Increasing the efficiency of investments in the road industry based on the formation of consolidated cost indexes (Istoki, Voronezh, 2006)

2. V.V. Gasilov, M.A. Shibaeva, FES: Finances. Economy. Strategy 1, 16-18 (2010)

3. V.V. Gasilov, G.I. Palagutin, M.A. Shibaeva, Optimization of the allocation of investment resources for road construction work (Istoki, Voronezh, 2007)

4. I.A. Provotorov, M.A. Shibaeva, Increase in the efficiency of concession projects (through the example of the road infrastructure of Voronezh Oblast) (Istoki, Voronezh, 2014)

5. I.A. Provotorov, Collection of articles of the $4^{\text {th }}$ International Scientific and Practical Conference in The place and role of Russia in the world economy (State Technology Academy, Voronezh, 2010)

6. M.A. Shibaeva, Proceedings of the International Scientific and Practical Conference in Economic Forecasting: Models and Methods 2007 (Voronezh State Technical University, Voronezh, 2007)

7. M.A. Shibaeva, Modeling the investment activity based on public and private partnership: theory, methodology, practice, Unpublished doctoral dissertation (Voronezh State Technical University, Voronezh, 2009)

8. M.A. Shibaeva, Modeling the investment activity in the road infrastructure based on public and private partnership (Istoki, Voronezh, 2009)

9. S. Korotkij, Neural networks. Backward propagation algorithm, http://ai.obrazec.ru/neur-2.html (2007) 